\title{
Evolution of Crystallographic Structures and Phases in Micropyretically Formed Boron Rich Boron Carbide - a New Material System
}

\author{
R.M. Mohanty, K. Balasubramanian and S.K. Seshadri \\ NonFerrous Materials Technology development Centre, \\ Kanchanbagh, Hyderabad
}

India

\section{Introduction}

The 'boron- carbon system' is a typical representative of hard refractory nonmetallic low Zceramic. Among various boron to carbon stoichiometry, the ratio higher than 2, are known as boron carbides. These offer many attractive advantage compared to any commercially available hard materials [1-2]. Beside the powder forms, the sintered shapes find wide spread application in ballistic, biomedical application and component engineering. In principle the binary B-C system exist with a number of stable and metastable configurations [3]. Many classical and non classical processes have been considered [4 -12] for producing boron carbides. Among them the researchers have reported on existence of rhombohedral boron carbide with stoichiometry ratio (B/C) near to 4:1.The widely adopted carbothermal process requires rapid heating of all particle separately and individually up to temperature range $2473 \mathrm{~K}$ to $2773 \mathrm{~K}$ to achieve significant conversion of input material in 5 hours to 24 hours. In almost all carbothermal processes it is reported to have agglomerated carbon rich boron carbide with boron value up to $78.8 \%$. As per the literature surveys, hardly any systematic investigation has been reported for existence of multiple phases in a single step solid state processing path. It is possible that selection or tailoring of properties for particular use can be made on basis of different stoichiometric phases of boron carbide [13].The presence of boron rich boron carbide can compensate the boron loss during boron carbide based solid body formation processes and thus preserves or improves the functional requirement. 'Vapor deposition' and 'boron doping' processes are the well studied processing methods which have confirmed the 'non stoichiometric existence of boron carbides' [3, 14.15]. With reference to above facts the research article discusses the structure and analytical development of many phases of boron carbide formed in a ' $\mathrm{B}_{2} \mathrm{O}_{3}-\mathrm{Mg}-\mathrm{C}^{\prime}$ micropyretic process with bulk boron to carbon ratio as 5.042:1[16].

\subsection{Crystal structure and stoichiometry}

In variety of boron based systems, the structure of low boron containing systems are determined by the metal lattices or semi metallic lattices. For boron-rich compounds, the 
structures are determined by their boron atoms which form covalent boron-boron lattices [17]. In these systems the non stoichiometry phenomenon arises from the existence of a broad free energy minimum in the free energy vs. composition diagram. This is facilitated either by the defects in boron chains or because of vacancies in the covalent lattices with a slight shift in lattice spacing [18-19]. The presence of these non-stoichiometric phases complicates the crystal structure elucidation. Different modifications of elementary boron and numerous compounds of it belonging to boron rich lattices exhibit a close similarity in their structures. The structure consisting of complicated three dimensional network of B12 or B11C (in case of B-C system) icosahedra or related aggregates of atoms as essential common structural elements. The structure of rhombohedral boron carbide is a modification of alpha-B12 structure [20 -21].In general the structure of B-C system is an arrangement of regular do-decahedrons at the nodes of a rhombohedral Bravais lattice ( $\mathrm{R}-3 \mathrm{M}$ space group) as shown in Fig.1.

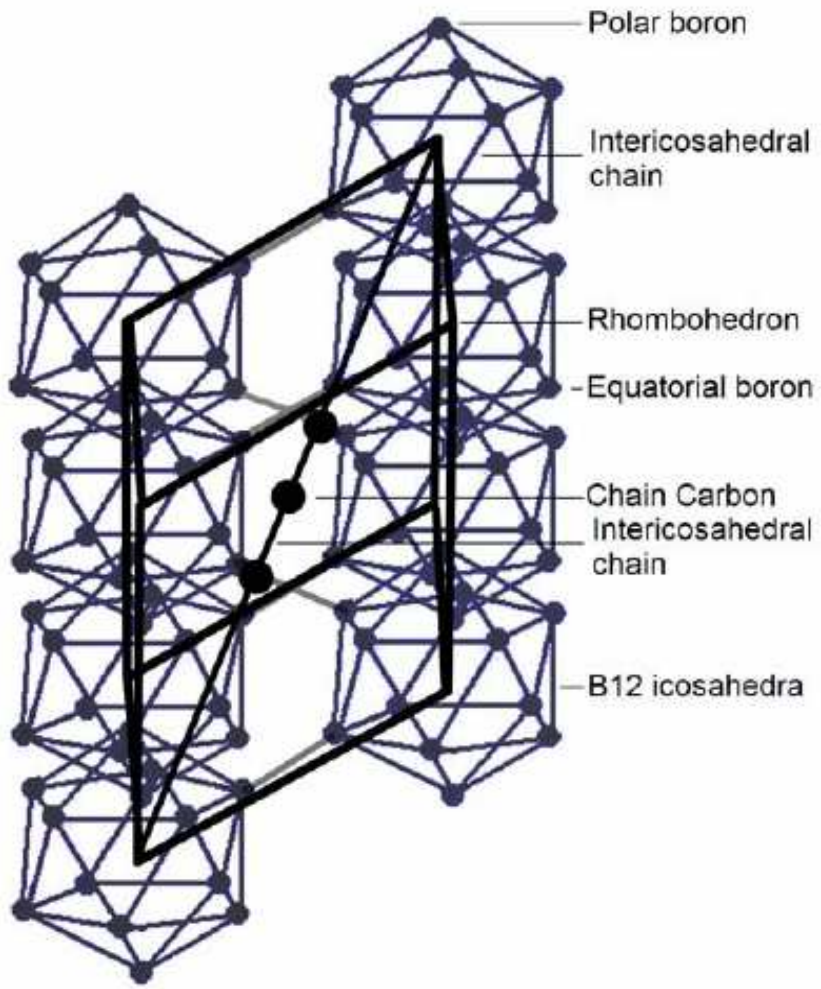

Fig. 1. Rhombohedral crystal structure of a stoichiometric boron carbide , B4C

The boron rich icosahedral structures reside at the vertices of a rhombohedron. Four sites are available for a total of 15 'B and $\mathrm{C}^{\prime}$ atoms in the crystal structure. Thus the B and C atoms can interchange each other within both icosahedral and inter icosahedral atom chains. This constitutes the basis for the large homogeneity range for $\mathrm{B}-\mathrm{C}$ system. Mostly the $\mathrm{C}$-atoms are 
along the diagonal of the rhombohedron forming the inter-icosahedral chains in chain configuration. The widely studied three carbon atoms as in $\mathrm{B}_{12} \mathrm{C}_{3}$ along the intericosahedral chain can be substituted all or in parts by vacancies or several types of atoms, thus forming the boron rich and carbon rich end of the stoichiometry [22]. The case of tetragonal structural unit for boron carbides is little different. It consists of four boron icosahedra in a tetragonal arrangement with two carbon atom and the two remaining boron atoms occupying inter-icosahedral sites.

\section{Experimental}

A thermal explosion process mode was used to form boron carbide using stoichiometric amount of high pure boron oxide with excess carbon and magnesium considering $\mathrm{B}_{4} \mathrm{C}$ as the expected product [16]. The input material were mixed in a high energy planetary ball mill, cold compacted and heat treated in presence of positive non-oxidizing gas pressure. The chemically purified products were collected and characterized in as formed as well as in crushed condition. The characterization techniques like $\mathrm{X}$-ray diffraction ( $\mathrm{Cu}$ anode), X-ray fluorescence techniques along with scanning electron microscopy were used to establish the products. The XRD pattern for the multi phases was compared with a high pure boron carbide standard with $\mathrm{B} / \mathrm{C}$ ratio as $4: 1$. The diffraction patterns were recorded using Bragg Brentano geometry at the room temperature over the angular range $8^{\circ}$ to $90^{\circ}$ in the step of $0.002{ }^{\circ}$ with 2 second as step time. A number of secondary experiments, graphical simulation and calculations were performed to confirm the presence of poly crystalline phases. These were carried out especially where the percentages of phases were less and when the pattern breaking was critical because of peak over laps, experimental, compositional, structural, machinery and algorithms limitations [23]. Lattice constants were calculated from the peak positions in the XRD profiles using peaks existing up to $50^{0}$ of two theta values.

\section{Result and discussion}

The effect of an limited penetrable boundary material such as carbon, on the reaction dynamics of a double species (B-C) reaction process in the low exothermic B-O-Mg-C system with diffusive reactants were studied [24]. The SEM micrographs showing the as formed and as chemically purified powders have been presented in the Fig.2. The purity was more than $99.97 \%$ with boron to carbon ratio determined as 5. 042 [16]. The observed x-ray diffraction pattern has been shown in Figure-3 with a comparative account with a standard obtained by thermally and chemically purifying a commercially available $\mathrm{B}_{4} \mathrm{C}$.As observed in the Fig. 3 a number of new peaks were found compared to the $\mathrm{B}_{4} \mathrm{C}$ standard.

Phase detection and quantification: In case of XRD analysis of rhombohedral boron carbides the strong (021) Debye ring is ideally located in between $36.764^{\circ}$ to $38.116^{\circ}$ and the ring (104) from $34.0760^{\circ}$ to $35.284^{\circ}$ of 2 -theta values. The relative peak positions of boron carbides depend on the carbon contents [25].Beside this fact, the data analysis of a multi phase pattern is always a complicated process. It happens specially in presence of factors like peak overlaps, continuous back grounds, variation in fixing of peak parameters, fixed algorithm, absorption, porosity, axial divergence of beam, radiation types, alignment problems, disorders, crystallinity, sample preparation, grain size and its uniformity [22, 25]. Such a problem becomes critical when the structural variation are narrow as found in $r-$ boron carbides. Considering the above discussed factors, during subsequent approaches and 
by search -match comparison with JCPDS-ICDD data the determined phases were as $\mathrm{B}_{13} \mathrm{C}_{2}$, $\mathrm{B}_{48} \mathrm{~B}_{2} \mathrm{C}_{2}, \mathrm{~B}_{41.11} \mathrm{C}_{4.45}, \mathrm{~B}_{12} \mathrm{C}_{3}, \mathrm{~B}_{8} \mathrm{C}, \mathrm{B}(\mathrm{T})$ and $\mathrm{B}$ (Rh) with JCPDS cards numbers as 33-0225,71-1107, 71-0363,35-0798, 26-0232,31-0206 and 78-1571 respectively. The phases were quantified in a semi quantitative manner using the combination of normalized RIR method [26], integrated intensities and mass absorption ratios. Through the semi-quantitative analysis give theoretically exact result, there are several source of as- discussed errors which prohibit an accurate result. However in any case the result is at least approximately correct [Philips electronic publication, Nov 2001]. Stepwise standard workouts were carried out to confirm the accuracy of the quantification [27].
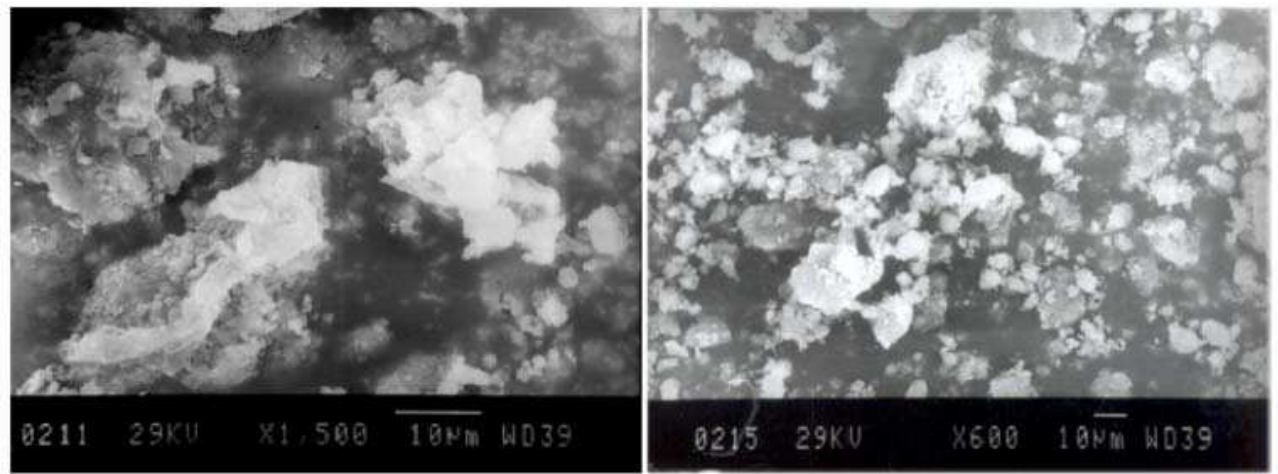

Fig. 2. SEM micrograph of (a) as formed product (b) the chemically purified product

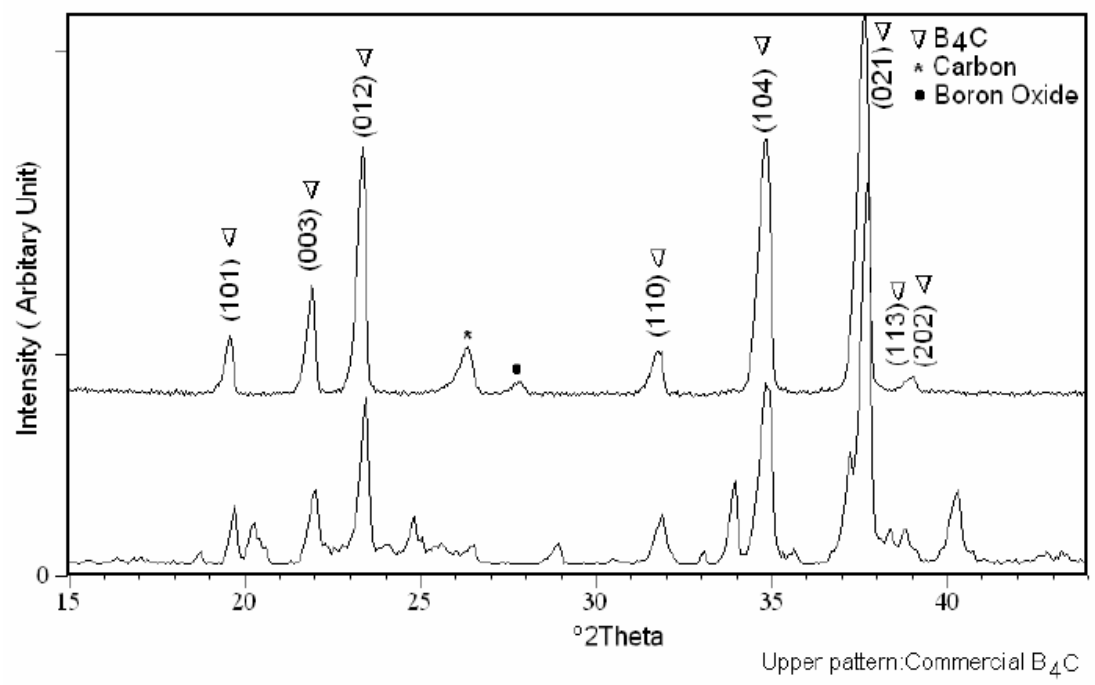

Lower pattern Ranges of boron carbide formed by $\mathrm{B}, \mathrm{O}_{3}-\mathrm{Mg}-\mathrm{C}$ system

Fig. 3. XRD peak comparison of a carbothermal and the micropyretic BC product

In this study, the peak shapes were determined using individual intensity convolution and peak shape functions (mainly a set of Psedo-Voigot functions). The intensity of boron rich 
peaks were found to be weak in compared to carbon rich boron carbides which have also been confirmed by a work of Disbudak and Silvestre et al. [28]. A variation in peak positions as observed for various rhombohedral boron carbides are explained to be the substitution of a carbon atom by a boron atom in the inter or intra icosahedrons $[19,21,22,28]$.The phase detection has also been confirmed by a multiphase simulation programme and the results have been represented by Fig. 4 .

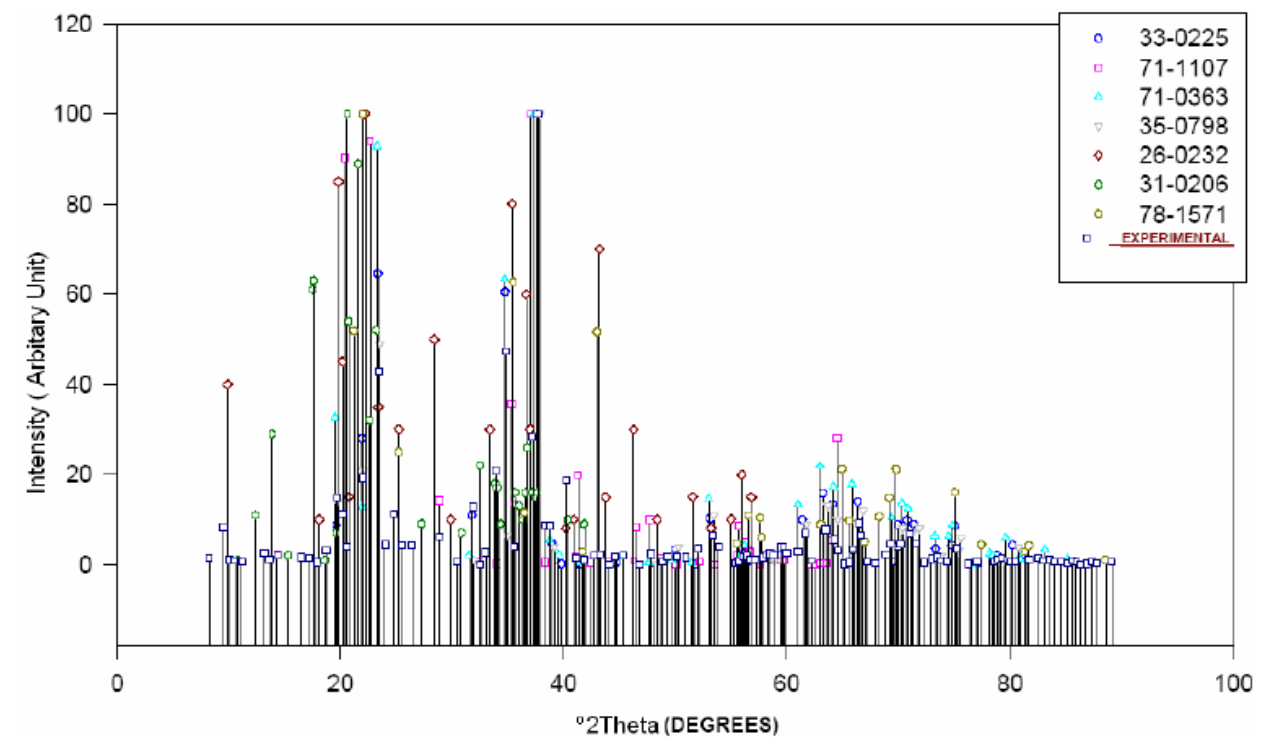

Fig. 4. Overlapped graph of experimental and simulated stick patterns

\subsection{Structure estimation}

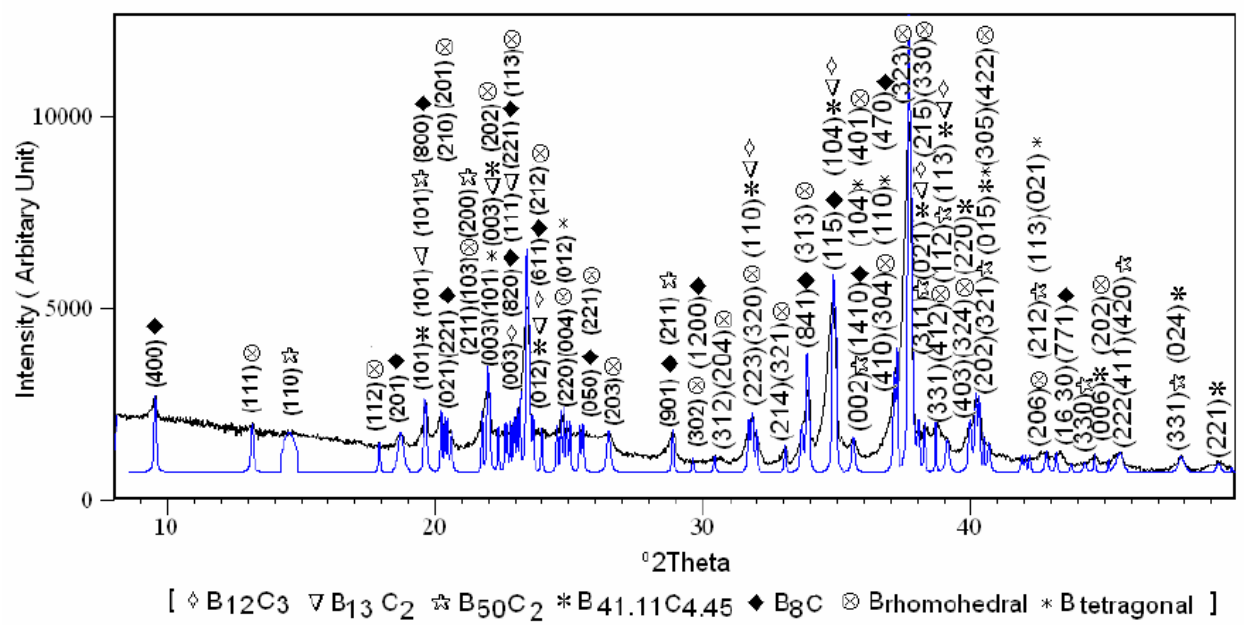

Fig. 5. Selected range of the multiphase, ab-initio indexed pattern 
The classical ways to obtain accurate unit cell parameters are full pattern decomposition and full profile based Rietveld refinement [29]. Since some of the parameter required for a Rietveld refinement are not known for the nonstoichiometric phases, the experimental pattern [ $8^{\circ}$ to $90^{\circ}$ range, $0.002^{\circ}$ step size] was structurally analyzed by defining the ab initio indexing to the determined 2-theta peak positions within $8^{\circ}$ to $50^{\circ}$ range (Fig.5). In total 42 peaks were used to find best lattice parameter sets for the multi phase pattern. The results were summarized as in the table- 1 and table- 2 which predict the existence of both tetragonal and rhombohedral borons along with rhombohedral, tetragonal and orthorhombic phases for boron carbides.

\begin{tabular}{|c|c|c|c|c|c|c|c|c|}
\hline $\mathrm{B}_{12} \mathrm{C}_{3}$ & $37.819^{\circ}$ & $37.747^{\circ}$ & (021) & 130.22 & $\mathrm{BC}_{4} \mathrm{C}$ & 3.589 & R-3M & 52.59 \\
\hline${ }^{B}{ }_{13} C_{2}$ & $37.604^{\circ}$ & $37.677^{\circ}$ & (021) & 114.29 & $\mathrm{~B}_{6.5} \mathrm{C}$ & 3.416 & R-3M & 42.41 \\
\hline $\mathrm{B}_{48} \mathrm{BC}_{2}$ & $37.059^{\circ}$ & $37.136^{\circ}$ & (311) & 32.12 & $\mathrm{~B}_{25} \mathrm{C}$ & 3.165 & $\mathrm{P}_{2} / \mathrm{nnm}$ & 02.30 \\
\hline $\mathrm{B}_{41.11} \mathrm{C}_{4,45}$ & $37.324^{\circ}$ & $37.324^{\circ}$ & (021) & 29.23 & $\mathrm{~B}_{9.24} \mathrm{C}$ & 3.320 & R-3M & 01.40 \\
\hline${ }_{\mathrm{B}} \mathrm{B} \mathrm{C}$ & $22.206^{\circ}$ & $22.013^{\circ}$ & (820) & 58.49 & ${ }_{\mathrm{B}} \mathrm{C}$ & 3.354 & $\mathrm{P}^{222}{ }_{1}$ & 00.80 \\
\hline $\mathrm{B}_{\text {(T) }}$ & $22.579^{\circ}$ & $22.590^{\circ}$ & (221) & 11.90 & - & 3.06 & $\mathrm{P}_{1}$ & rest \\
\hline $\mathrm{B}_{(\mathrm{RH})}$ & $21.982^{\circ}$ & $22.020^{\circ}$ & (101) & 29.54 & - & 3.06 & R-3M & rest \\
\hline
\end{tabular}

Table 1. Observed experimental values with standard available values for the multiphase pattern

\subsection{Explanation to observed result}

Most of the reported solid state processes $[10,12,30]$ produce single phase boron carbide. The discussed experimentation process is initially a solid state process. With increase of temperature the $\left(\mathrm{B}_{2} \mathrm{O}_{3}-\mathrm{C}-\mathrm{Mg}\right)$ system with high carbon acts like a 'colloidal system'. Local melting in the vicinity of the reacting species has an appreciable effect on the equilibrium interfacial concentrations and the diffusion co-efficient in contacting phases. The decrease in the exothermicity because of presence of low melting glassy $\mathrm{B}_{2} \mathrm{O}_{3}$, is adequately compensated by the external heating. The excess external heat sustained the reactive process to attain the adiabatic temperature and the colloidal condition assisted in suppression of initial reduction products like $\mathrm{B}_{2} \mathrm{O}_{3}$ and thus the other sub oxides or gaseous species [31]. These along with the prevailing reaction conditions in the "high pressure changed environment" prevented the formation of ' $\mathrm{MgC}_{2}$ or $\mathrm{MgB}_{2}$. As a result, the expected reactive interactions were achieved. The products were mostly B-C and $\mathrm{Mg}-\mathrm{O}$ based compounds. Presence of carbon as buffer reduced the formation of $\mathrm{MgO}_{2}, \mathrm{Mg}_{2} \mathrm{~B}_{2} \mathrm{O}_{6}$ with a self adjustment to $\mathrm{CO}$ activity in the closed furnace environment. 


\begin{tabular}{|c|c|c|c|c|c|c|c|c|c|c|}
\hline Phases & $a_{e x p}\left(a_{e s t a j}\right) A^{0}$ & $b_{\text {exp }}\left(b_{\text {estat }}\right) A^{0}$ & $C_{\text {exp }}\left(C_{\text {estab }}\right) A^{0}$ & & i) $\beta$ & (i) $r()$ & Synd.FOM & I Sp.gr. sym. & $V_{\text {exp }}\left(V_{\text {estal }}\right) \cdot\left(A^{0.3}\right.$ & $\left.\mathrm{A}^{03}\right)$ Data type \\
\hline $\mathrm{B}_{12} \mathrm{C}_{3}$ & $\begin{array}{c}5.616(2) \\
{[5.6003(5)]}\end{array}$ & $\begin{array}{c}5.616(2) \\
{[5.6003(5)]}\end{array}$ & $\begin{array}{r}12.129(8) \\
{[12.086(2)]}\end{array}$ & $\begin{array}{c}90 \\
90\end{array}$ & 90 & $\begin{array}{c}120 \\
120\end{array}$ & $\begin{array}{l}28.905 \\
{[58]}\end{array}$ & $\begin{array}{l}\text { R-3M(166)H } \\
\text { R-3M(166)H }\end{array}$ & $\begin{array}{rr}331.291 & \\
{[328.270]} & 19\end{array}$ & $\begin{array}{l}\text { Experimental } \\
\text { 1984,Exper. }\end{array}$ \\
\hline $\mathrm{B}_{13} \mathrm{C}_{2}$ & $\begin{array}{l}5.877(4) \\
{[5.633]}\end{array}$ & $\begin{array}{l}5.877(4) \\
{[5.633]}\end{array}$ & $\begin{array}{l}12.17(1) \\
{[12.164]}\end{array}$ & $\begin{array}{l}90 \\
90\end{array}$ & $\begin{array}{l}90 \\
90\end{array}$ & $\begin{array}{l}120 \\
120\end{array}$ & $\begin{array}{c}12.1365 \\
{[103]}\end{array}$ & $\begin{array}{l}\text { R-3M(166)H } \\
\text { R-3M(166)H }\end{array}$ & $\begin{array}{r}364.017 \\
334.260\end{array}$ & $\begin{array}{l}\text { Experimental } \\
1980 \text {, Calcu. }\end{array}$ \\
\hline $\mathrm{B}_{45} \mathrm{~B}_{2} \mathrm{C}_{2}$ & $\begin{array}{l}8.770(7) \\
{[8.722]}\end{array}$ & $\begin{array}{l}7.241(7) \\
{[8.722]}\end{array}$ & $\begin{array}{l}6.176(6) \\
{[5.080]}\end{array}$ & $\begin{array}{l}90 \\
90\end{array}$ & $\begin{array}{l}90 \\
90\end{array}$ & $\begin{array}{l}90 \\
90\end{array}$ & $\begin{array}{c}13 \\
5.701\end{array}$ & $\begin{array}{l}\mathrm{P}_{2} / \mathrm{nnm}(134) \\
\mathrm{P}_{2} / \mathrm{nnm}(134)\end{array}$ & $\begin{array}{l}392.250 \\
386.450\end{array}$ & $\begin{array}{l}\text { Experimental } \\
\text { 1997,Calcu.. }\end{array}$ \\
\hline $\mathrm{B}_{41.11} \mathrm{C}_{4,45}$ & $\begin{array}{l}5.211(4) \\
{[5.672]}\end{array}$ & $\begin{array}{l}4.847 \\
{[5.672]}\end{array}$ & $\begin{array}{c}8.962(9) \\
{[12.1428]}\end{array}$ & $\begin{array}{l}90 \\
90\end{array}$ & $\begin{array}{c}90 \\
90\end{array}$ & $\begin{array}{l}112.06 \\
120\end{array}$ & 23.000 & $\begin{array}{l}\text { R-3M(166)H } \\
\text { R-3M(166)H }\end{array}$ & $\begin{array}{ll}211.000 \\
338.320\end{array}$ & $\begin{array}{l}\text { Experimental } \\
\text { 1997,Calcu.. }\end{array}$ \\
\hline $\mathrm{B}_{8} \mathrm{C}$ & $\begin{array}{l}20.809 \\
{[35.909]}\end{array}$ & $\begin{array}{l}4.503(3) \\
{[17.653]}\end{array}$ & $\begin{array}{c}4.109 \\
{[5.094]}\end{array}$ & $\begin{array}{l}90 \\
90\end{array}$ & $\begin{array}{l}90 \\
90\end{array}$ & $\begin{array}{l}90 \\
90\end{array}$ & $\begin{array}{r}14 \\
2\end{array}$ & $222_{1}(17)$ & $\begin{array}{c}386.66 \\
3229.09\end{array}$ & $\begin{array}{l}\text { Experimental } \\
\text { Single crystal }\end{array}$ \\
\hline $\mathrm{B}_{(\mathrm{I})}$ & $\begin{array}{l}9.443(9) \\
{[10.140]}\end{array}$ & $\begin{array}{l}9.443(9) \\
{[10.140]}\end{array}$ & $\begin{array}{l}8.322(7) \\
{[14.170]}\end{array}$ & $\begin{array}{l}90 \\
90\end{array}$ & $\begin{array}{l}90 \\
90\end{array}$ & $\begin{array}{l}90 \\
90\end{array}$ & $\begin{array}{c}5.744 \\
73\end{array}$ & $\begin{array}{l}\mathrm{P4}_{1}(76) \\
\mathrm{P}_{1}\left({ }^{76}\right)\end{array}$ & $\begin{array}{rr}749.954 & \mathrm{E} \\
1456.95 & \mathrm{C}\end{array}$ & $\begin{array}{l}\text { Experimental } \\
\text { Calculated. }\end{array}$ \\
\hline $\mathrm{B}_{(\mathrm{Rh})}$ & $\begin{array}{l}3.2776 \\
{[4.927(3)]}\end{array}$ & $\begin{array}{l}3.2776 \\
{[4.927(3)]}\end{array}$ & $\begin{array}{c}36.38 \\
{[12.564(7)]}\end{array}$ & $\begin{array}{l}90 \\
-\end{array}$ & $\begin{array}{r}90 \\
-\end{array}$ & $\begin{array}{c}120 \\
-\end{array}$ & $\begin{array}{l}9.9937 \\
7.745428\end{array}$ & $\begin{array}{l}\text { R-3 M(166)H } \\
\text { R-3 M(166)H }\end{array}$ & $\begin{array}{l}336.8905 \\
264.13\end{array}$ & $\begin{array}{l}\text { Experimental } \\
\text { Calculated. }\end{array}$ \\
\hline
\end{tabular}

Notation : "exp.(experimental finding) *estb.(established value from literatures) * FOM (Figure of merit) *Calcu.(Calculated)

Table 2. Crystal structure values as deduced from the indexed peaks in the multi-phase pattern

Considering the experimental results and the above analysis, a non-equilibrium mechanism is proposed. The global behavior of such a process depends on limiting factors like, the number of particles that interact locally in a single step and the dynamics of the reacting phases. Considering the report of combustion process achievements ( maximum adiabatic temperature, combustion propagation rate, rate of heating, and thermal gradient ) and the behavior of inputs, the phase formation in the process is proposed to have occurred in a non isothermal condition with existence of normal diffusive to ballistic diffusive behaviors. The diffusion length, inter effect of particles growth were found to be less and the $\mathrm{MgO}$ growth is not determined to be higher [figure-2]. Considering the above discussions, ignoring the Langmuir adsoption and basing on Fick's second law, a self consistent equation is defined for the process as

$$
\frac{\partial \bar{\rho}_{\mathrm{r}}}{\partial \mathrm{t}}=\mathrm{D}_{\mathrm{T}} \nabla^{2} \bar{\rho}_{\mathrm{r}}-2 \mathrm{k} \cdot \bar{\rho}_{\mathrm{r}}^{2}
$$

where $\mathrm{k}$ represents the slower kinetic term, $\mathrm{D}_{\mathrm{T}}$ as diffusion constant at corresponding temperature, $\bar{\rho}_{\mathrm{r}}$ is the average density of reacting phases and $\frac{\partial \bar{\rho}_{\mathrm{r}}}{\partial \mathrm{t}}$ is the rate of decay of reacting phases. Under present condition the product phase concentration is dependent more on the mean free path rather on ' $\mathrm{k}^{\prime}$ or ' $\mathbf{D}_{\mathrm{T}}$ '. Since the spatial dimension of the process path is low i.e. two dimensional, at any time, reacting phases those are close to each other react at a faster rate compared to widely separated one. This explains the formation of ' $\mathrm{mix}$ phases' with the importance of process input homogeneity. The limit to achieve theoretical yield value is much dependent on 'before process interaction homogeneity'. Thus the 
possibilities associated with a simple type of propagating 'non equilibrium heat wave' is generalized as in the Fig.6.

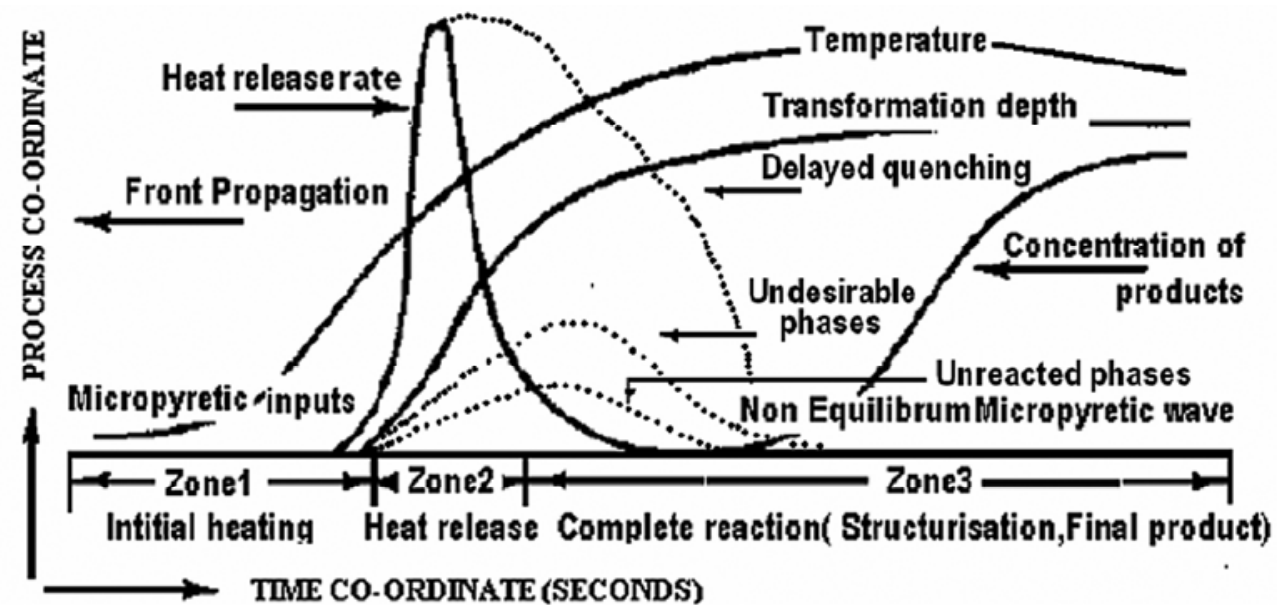

Fig. 6. A typical presentation of associated non equilibrium micropyretic wave

The multiphase boron carbides formation can be explained in the following ways. Above $1400 \mathrm{oC}$ with relatively longer reaction time, the formation of $\beta$-rhombohedral boron or the tetragonal elementary boron is possible with a three dimensional net work of B12 clusters [32]. Among them $\beta$-rhombohedral boron is more stable but its survival as an elementary phase depends on the existing high temperature thermodynamics. The formation of both type borons as found in this study also supported by an earlier published work [32]. Concerning the formation of tetragonal boron, as per Gmelin et al carbon helps in stabilizing the tetragonal boron [33]. In this current high pressure experiment carbon was one of the excessive input.The diffusion of boron and carbon to one another crystal lattices are also possible. However the diffusion length is limited by the involved high temperature kinetics. Again reports of C.E. Lowell et al reveal the maximum solubility of B in C(gr) as 2.35 at $\%$ at $2350^{\circ} \mathrm{C}$ if interstitial formation is neglected [34]. Boron has a diffusivity of $2.028 \times 1011 \mu \mathrm{m}$ $2 / \mathrm{sec}$ for others lattices at $1000 \mathrm{oC}$. The phase formation results along with the predictions of mentioned literatures favour the formation of B-C lattice on carbon particle with diffusion of $\mathrm{C}$ into the developing B-lattice. Thus in boron rich boron carbides the primary bonding is BB. The arrangement of boron structures depending on its relative activity in a compound can be summarized as in Fig.7.

Earlier the formation of tetragonal boron carbide with less than $10 \% \mathrm{C}$-content had been reported by CLJ Adkins and other [35]. As per them this occurs mostly under carbon depletion conditions compared to that exist for the rhombohedral form. The presence of the tetragonal boron, short processing time [Fig. 6], the time based consumption of carbon along with the high diffusion coefficient of boron indicate tetragonal boron carbide is a modification of tetragonal boron. And the conversion process is a consecutive process. The relative percentage of its formation is affected by the prevailing heating conditions in the furnace and the reactants homogeneity. According to Aselage et al. the thermodynamic instability of pure $\beta$-rhombohedral boron allows the formation low $\mathrm{C}$ - 
rhombohedral boron carbide. This supports the experimental result of getting a range of rhombohedral boron carbides and also may be an out come of increased chemical potential of B or reduced chemical potential of $\mathrm{C}$. The presences of larger unit cell of boron carbides suggest the reduced carbon concentration. A comparative study of $\beta$ rhombohedral boron and boron carbide spectra with different $\mathrm{C}$-concentration has been reported by Tallant et al. [37]. The main structural difference in-between them is the presence of a CBC linear chain in the boron carbides [26,38,39]. Like boron, rhombohedral boron carbide also has a crystalline icosahedral appearance with B12 cluster as a part of its structure. Thus the above evidences and all results favour the formation of B-C system from elementary boron.

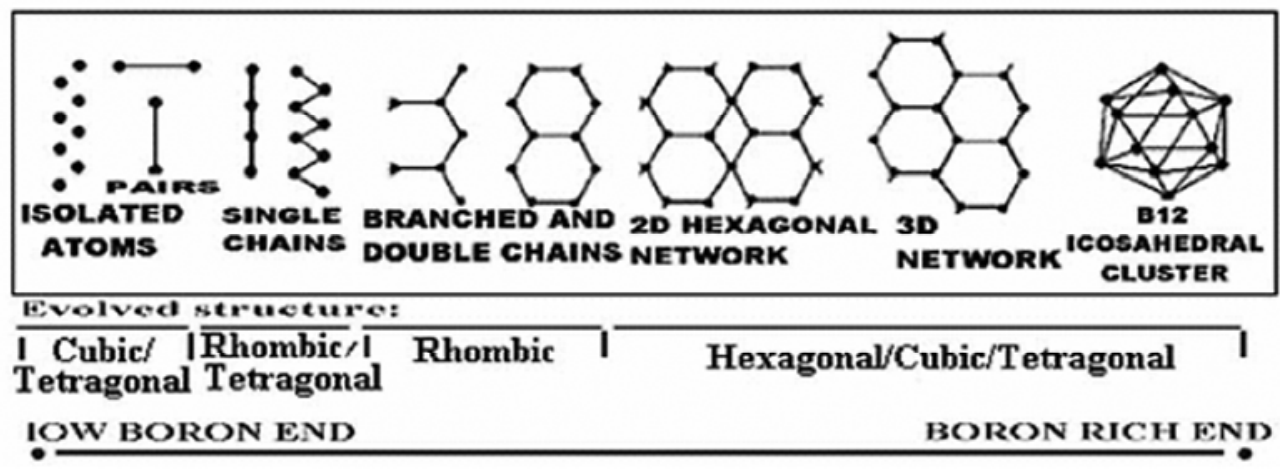

Fig. 7. Relative prediction of structural development in boron based system

\section{Conclusion}

Experimental data obtained during the investigation and subsequent analysis predict the existence of a range of boron carbides and borons like $\mathrm{B}_{13} \mathrm{C}_{2}, \mathrm{~B}_{48} \mathrm{~B}_{2} \mathrm{C}_{2}, \mathrm{~B}_{41.1} 1 \mathrm{C}_{4.45}, \mathrm{~B}_{12} \mathrm{C}_{3}, \mathrm{~B}_{8} \mathrm{C}$, $\mathrm{B}(\mathrm{T})$ and $\mathrm{B}(\mathrm{Rh})$ in the single step solid state process. The other findings of the study are summarized as

1. Both 'rhomohedral and tetragonal' boron are formed as in-situ reactive products.

2. The nature and the stability of this insitu boron decide the type of boron carbide thus formed. In other word, varying multiple heat waves as obtained in the micropyretic process and the prevailing reaction conditions like steady heat wave formation, vortex detachment or quenching (heat flow stability), coupling between the pressure wave and combustion assist the formation of the boron carbides with varying crystallographic structures.

3. Absence of carbon rich boron carbide shows the diffusion of boron to carbon lattice is limited and even show at high temperatures.

4. Tetragonal boron carbide forms under carbon depletion condition with availability of tetragonal borons.

5. Thermodynamic and kinetic instability of pure rhombohedral borons leads to the formation of low carbon boron carbides. The existence of a range of rhombohedral boron carbide is a out come of either the increased chemical potential of $r$ - boron or the decreased chemical potential of the carbon in the local chemical environment. 
6. The foamy and less agglomerated crude products obtained from the reactive process indicate the existence of high reaction rate and low partial surface energy. And the reaction mechanics of the process enables the obtaining of both equilibrium and non equilibrium boron based powders of high purity with a low micron size good particle dispersity.

7. Type and quantity of insitu boron controls the percentage and structure formation of boron carbides.

\section{References}

[1] Knoch, H, Steinmann, D., Ceramic bearings and abrasion resistant components from silicon nitride, silicon carbide and boron carbide, Metall (J. South African Institute of Mining and Metallurgy) 43/3(1989), 250-254,

[2] Umeda, K., Enomoto, Y., Mitsui, A., Mannami, K., Tribological properties of boron carbide, Japanese J. tribology,40/2(1995),53-64.

[3] Nihara, K, Nakahira, A, Hirai, H. The effect of stoichiometry on mechanical properties of boron carbide, Commn.Am.Cer.soc, 67(1984), C13-14.

[4] Sinha A, Mahata, T, Sharma, B .P., Carbothermal route for preparation of boron carbide powder from boric acid-citric acid gel precursor, J.Nuc.materials, 301(2002), 165169.

[5] Thevenot, F, Boron carbide- A comprehensive review, J.Europ.Cer. Soc, 6 (1990), 205207.

[6] Weimer, A.W., Moore, W. G., Roach, R. P., Hitt, J .E., Dixit, R.S., Pratsinis S.E., Kinetics of Carbothermal reduction synthesisb of boron carbide, Al Che.Journal 37 (1991),759.

[7] FreireJr, F.L., Reigada , D.C., Priolli, R, Boron carbide and boron-carbon nitride films deposited by DC sputtering, Phys.state.Soc.A (2001),1871.

[8] Radev, D.D., Boron Carbide, Part 1: Synthesis of Powders, Metall, 51/10 (1997),564567.

[9] Goller, G., Toy, C., Tekin, A., Gupta, C.K., The production of boron carbide by carbothermic reduction, High temp.Mat.Procs.15/1-2 (1996),117-122.

[10] Sung-won Jo, Lee, G., Moon , J ., Kim, Y ., On the formation of MoSi2 by selfpropagating high-temperature synthesis, J.Mat.Sc.Lett.19 (2000), 951-954.

[11] Mierze Jewska, S., Niemyski, J. J, Formation of Group- IVb Carbides, J.less common metals, 8(1965), 368

[12] Junga, C.H., Leeb, M. J., Kima, C. J., Preparation of carbon- free B4C powder from B2O3 oxide by carbothermal reduction process, Mat.Lett. 58(2004), 609-614.

[13] Dobrova, M B, Kozynkin, B. I., Kalvgin, V. I., Agafonov, A .V., Fadeev , A. A., Sidorenko, E. S., Optimizing neutron detection with semiconducting Boroncarbide, J.Adv.Mater.11(1994),69-73.

[14] Ploog, K., Gasphasenabscheidung von binären Bor - Kohlenstoff -Phasen bei Substrattemperaturen von 900 bis $1800^{\circ} \mathrm{C}$ I. Tetragonales und orthorhombisches Borcarbid. J.less common metals 5/1 (1974),115-130.

[15] Sezer, A.O., Brand, J.J., Chemical vapor deposition of boron carbide, Mater. Sci. Eng, B79 (2001), 191-202. 
[16] Mohanty, R.M., Balasubramanian ,K., Seshadri, S.K, Multiphase formation of boron carbide in B2O3-Mg-C based micropyretic process, J. alloys compd, 441 (2007), 8593.

[17] Samsonov, G.V., Serebryakova, T.I., Boron compounds with group VI elements, Sov.Powder Metall.Met.Ceramic (English trans.)17/2 (1978) 116-120

[18] Mc Colm, I.C., Ceramic Science for materials technologist, Leonard Hill, London (1983), 330-343.

[19] Schwarzkoff, P., Kieffer, R., Refractory hardmetals (1953), Mac Millan.

[20] Lazzari, R., Vast, N ., Besson, J. M., Baroni, S., Corso, A .D. , Atomic structure and vibrational properties of icosahedral B4C boron carbide, Phys. Review Lett.. 83/16 (1999), 3230.

[21] Fujimori, M., Nakata, T., Nakayama1, T., Nishibori, E., Kimura, K., Takata, M., Sakata, M., Peculiar covalent bonds in a-RhombohedralBoron, Phys.Rev.lett 82 (1999),4452-4455.

[22] Samsonov, G. V., Vinitskii, I. M., Handbook of refractory compounds, Plenum press (1980), New York.

[23] Suematsu, H., Kitajima, K., Ruiz, J., Kobayshi, K., Takeda, T., Shimdo, D ., Suzuki, T., Jiang, W ., Yatsui, K, Thermoelectric properties of crystallized boron carbide thin films prepared by ion-beam evaporation, Thin solid films, 407 (2002),133.

[24] Lowell C E, Solid Solution of Boron in Graphite. J. Am. Ceram. Soc. 50 (1967), 142-144.

[25] Chung, F.H., Quantitative interpretation of X-ray diffraction patterns: I. Matrix-flushing method of quantitative, J.App.Cryst.. 7 (1974),513-519.

[26] Synder, R.L., The use of reference intensity ratios in X-ray quantitative analysis, Powdiff. 7 (1992), 186-193.

[27] Conde, O., J Silvestre, A., Oliveira1, J .C., Influence of carbon content on the crystallographic structure of boron carbide, Surf. Coat. Technol. 125 (2000),141.

[28] Silvestre, A.J., Santoss , M.J., Conde, O., The Role of Carbon Precursor on boron carbide Synthesis by Laser-CVD , Key Eng. Mater 56 (2002),230-232.

[29] Stoto, N.H., Zuppiroli, L. Swelling and microcrackin of boron carbide subjected to fast neutron irradiations, J.App. Phys. 68/7 (1990). 3198.

[30] Bougoin, $M$,, Thevenot, F., Synthèse et caracterisation de ceramiques denses en carbure de bore, J.Less Common.Metals,114(1985), 257-271.

[31] Southard, J.C., Thermodynamic of boron compounds, J. Am. Chem. Soc. 63(1941),3147.

[32] Vandenbulcke, L., Vuillard, G., Polymorphism in boron deposited by the H2 reduction of BC13, J.Less.Commo.met.67(1979) p65.

[33] Gmelin, Boron (System No.13) Supliment Vol.2, Unidentified publication,1981

[34] Lowell ,C.E., Solid solution of boron in Graphite, J.Am. Ceram. Soc., 50 (1967),142144.

[35] Adkins, C.L.J., Cambell, A.M., Headley, T.J., Synthesis of high temperature materials, VCH Publishers, New York (1990.) 391-398,

[36] Aselage, T.L., Van Deusen, S.B.., Morosin, B., Solution growth, structure and composition of boron carbide crystals, J.Less. Comm. Metals. 166/1(1990), 29-44.

[37] Tallant D , Aselage, T, Cambell, A, Emin D., Boron carbide structure by Raman spectroscopy, Physical Rev.B 8 (1989), 5649. 
[38] R.M. Mohanty, K. Balasubramanian, Boron Rich Boron Carbide: An Emerging High Performance Material, Progress in High Temperature Ceramics (ISBN: 0-87849-361-1) KEMV395, pages 125-142, Trans Tech Publications Inc., Switzerland 2009.

[39] R.M. Mohanty, K. Balasubramanian , P.Horidoss, S.K. Seshadri , Compositional and structural variations in solid state formed boron carbide, Recent advances in composite materials (Intelligent, smart, Sustainable \& Infrastructural Materials) (ISBN:81-8424-175-5) pages 580-586, Allied Publisher Limited, 2007. 


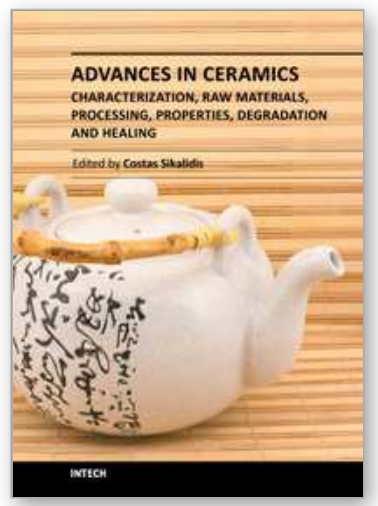

\author{
Advances in Ceramics - Characterization, Raw Materials, \\ Processing, Properties, Degradation and Healing \\ Edited by Prof. Costas Sikalidis
}

ISBN 978-953-307-504-4

Hard cover, 370 pages

Publisher InTech

Published online 01, August, 2011

Published in print edition August, 2011

The current book consists of eighteen chapters divided into three sections. Section I includes nine topics in characterization techniques and evaluation of advanced ceramics dealing with newly developed photothermal, ultrasonic and ion spattering techniques, the neutron irradiation and the properties of ceramics, the existence of a polytypic multi-structured boron carbide, the oxygen isotope exchange between gases and nanoscale oxides and the evaluation of perovskite structures ceramics for sensors and ultrasonic applications. Section II includes six topics in raw materials, processes and mechanical and other properties of conventional and advanced ceramic materials, dealing with the evaluation of local raw materials and various types and forms of wastes for ceramics production, the effect of production parameters on ceramic properties, the evaluation of dental ceramics through application parameters and the reinforcement of ceramics by fibers. Section III, includes three topics in degradation, aging and healing of ceramic materials, dealing with the effect of granite waste addition on artificial and natural degradation bricks, the effect of aging, micro-voids, and self-healing on mechanical properties of glass ceramics and the crack-healing ability of structural ceramics.

\title{
How to reference
}

In order to correctly reference this scholarly work, feel free to copy and paste the following:

R.M. Mohanty, K. Balasubramanian and S.K. Seshadri (2011). Evolution of Crystallographic Structures and Phases in Micropyretically Formed Boron Rich Boron Carbide - a New Material System, Advances in Ceramics - Characterization, Raw Materials, Processing, Properties, Degradation and Healing, Prof. Costas Sikalidis (Ed.), ISBN: 978-953-307-504-4, InTech, Available from: http://www.intechopen.com/books/advances-inceramics-characterization-raw-materials-processing-properties-degradation-and-healing/evolution-ofcrystallographic-structures-and-phases-in-micropyretically-formed-boron-rich-boron-carb

\section{INTECH}

open science | open minds

\author{
InTech Europe \\ University Campus STeP Ri \\ Slavka Krautzeka 83/A \\ 51000 Rijeka, Croatia \\ Phone: +385 (51) 770447 \\ Fax: +385 (51) 686166 \\ www.intechopen.com
}

\author{
InTech China \\ Unit 405, Office Block, Hotel Equatorial Shanghai \\ No.65, Yan An Road (West), Shanghai, 200040, China \\ 中国上海市延安西路65号上海国际贵都大饭店办公楼 405 单元 \\ Phone: +86-21-62489820 \\ Fax: +86-21-62489821
}


(C) 2011 The Author(s). Licensee IntechOpen. This chapter is distributed under the terms of the Creative Commons Attribution-NonCommercialShareAlike-3.0 License, which permits use, distribution and reproduction for non-commercial purposes, provided the original is properly cited and derivative works building on this content are distributed under the same license. 